\title{
АНАЛИЗ ФИНАНСОВОЙ УСТОЙЧИВОСТИ НЕФТЕГАЗОВОГО СЕКТОРА В УСЛОВИЯХ ДЕЙСТВИЯ ЭКОНОМИЧЕСКИХ САНКЦИЙ
}

\author{
(C) 2021 Иззука Татьяна Борисовна \\ кандидат экономических наук, доцент \\ Департамент бизнес-аналитики Факультета налогов, аудита и бизнес-анализа \\ Финансовый университет при Правительстве Российской Федерации, Россия, Москва \\ E-mail: TBIzzuka@fa.ru \\ (c) 2021 Рязанцева Виктория Даниловна \\ студент 3 курса, группа У19-6у \\ Факультет налогов, аудита и бизнес-анализа \\ Финансовый университет при Правительстве Российской Федерации, Россия, Москва \\ E-mail: viktoria1203@list.ru
}

За последние несколько лет мир стремительно изменился. Рынок углеводородного сырья за последние 2 года имеет значительную амплитуду колебаний. За 2020 год объем добычи нефти в странах, входящих в ОПЕК+, сократился на 43\% согласно представленному отчету. В России вирус COVID-19 появился в марте 2020 года, поэтому, рассматривая отчетность нефтегазового сектора, следует учитывать не только влияние сделки ОПЕК+, где основная доля сокращения добычи нефти пришлась на Россию, но и существенное падение спроса на углеводороды из-за глобального локдауна и остановки производства. Такое падение спроса на мировых рынках сказалось не только на крупнейших экспортерах нефти и газа, но и на доходах федерального бюджета, так как доходы от углеводородного экспорта занимают значительный удельный вес в структуре доходов федерального бюджета, только поступление налогов за пользование природными ресурсами в 2020 году сократилось на 8,9\%. Кроме того, «зеленая» энергия, переход на которую прогнозируют в ближайшее десятилетие, требует не только существенных затрат на ее производство, но и те отходы, которые будут возникать при ее производстве, загрязняют экологию еще больше, поэтому в ближайшие десятилетие рынок углеводородов будет сохранять свое лидерство не только в России, но и на мировых рынках. Если рынок нефти сегодня относительно стабилен, то из-за заполненных на $75 \%$ европейских хранилищ газа рынок лихорадит в значительной степени, так только за период с сентября по октябрь 2021 фьючерсы за 1 тысячу кубических метров газа выросли с $500 \$$ до 1900\$, затем после достижения своего пика упали на 36\%. Такая динамика может сохраниться, пока Европейский союз и «Газпром» не придут к соглашению, так как транзит через Украину невозможен ввиду отсутствия экономических выгод.

В данной статье рассмотрено влияние пандемии и действия экономических санкций и иных ограничений на финансовую устойчивость нефтегазового сектора посредством изучения финансовой отчетности организаций, для этого были исследованы крупнейшие экспортеры нефти и газа с позиции коэффициентного анализа финансовой устойчивости, а также произведена рейтинговая оценка для определения класса финансовой устойчивости.

Основной целью анализа финансовой устойчивости является оценка степени независимости организаций нефтегазового сектора от заемных источников финансирования. В процессе анализа финансовой устойчивости выясняется, в какой степени организация независима от привлечённых источников финансирования, растет или снижается уровень этой независимости, и в каком состоянии находятся активная и пассивная части баланса. Для получения необходимой информации, позволяющей достоверно и в полной мере описать финансовое состояние экономического субъекта, необходимо произвести расчёты ряда коэффициентов финансовой устойчивости.

Ключевые слова: финансовая устойчивость, коэффициенты финансовой устойчивости, нефтегазовый сектор, пандемия, чистая прибыль, динамика, рейтинговая оценка. 


\section{Введение}

Действия Российской Федерации на политической арене в 2014 году стали поводом для введения США и Европейским союзом экономических санкций. С момента введения экономических санкций против Российской Федерации прошло более шести лет, и с тех пор санкционный список пополняется новыми ограничениями. Наиболее уязвимыми отраслями под влиянием санкций оказались нефтегазовая и банковская отрасль, а также сельское хозяйство и если в банковской сфере появилась национальная платежная система «МИР», в сельском хозяйстве программа импортозамещения, то динамика цен на нефть на биржевых рынках существенно влияет не только на крупнейшие нефтегазовые корпорации, но также и на доходную часть федерального бюджета, значительную долю в 2021 году до сих пор занимает налоги, получаемые от добычи и экспорта нефти и газа.

В 2014 году во всей нефтегазовой отрасли возникли проблемы с импортом оборудования для добычи нефти и газа, так, зависимость от импорта оборудования составляла по разным оценкам около 80\%, первоначально нефтегазовым компаниям пришлось переориентироваться на закупку оборудования в КНР. Однако последние несколько лет происходит наращивание производства отечественного бурового оборудования, что позволяет снизить влияние санкций на нефтегазовую отрасль, при этом влияние политических заявлений западных лидеров на котировки нефти по-прежнему велико.

Под действиями санкций началось строительство Северного потока-2 и несмотря на значительные ограничения и суды, газопровод был введен в эксплуатацию осенью 2021 года, введенные ограничения спровоцировали газовый кризис в Европе и позволили крупнейшему поставщику газа в Европу получить не только прибыль, но и дополнительные доходы.

\section{Практическая часть}

Динамика чистой прибыли крупнейших нефтегазовых компаний, среди которых Газпром, Роснефть, Лукойл, Новатэк, Татнефть, Сургутнефтегаз не имеет однозначной тенденции к росту или снижению, поскольку доходы от прочей деятельности у данных компаний отличаются не только объемами, но и финансовым результатом. Так, двухкратное увеличение прочих расходов в компании Газпром привело к убытку в размере 707925 млн. руб.. Сургутнефтегаз наращивая доход от прочей деятельности в период пандемии и сокращая прочие расходы смог увеличить чистую прибыль в 7 раз, тем самым минимизировав эффект от действия сделки ОПЕК+ по сокращению добычи нефти и падения спроса на углеводородное сырье.

Сравнивая динамику чистой прибыли (см. рис. 1), нельзя сделать однозначного вывода о влиянии пандемии и действия сделки ОПЕК+ на финансовые результаты компаний-экспортеров, поскольку в показатель чистой прибыли закладывается доход от прочей деятельности, поэтому необходимо оценить динамику выручки за период с 2019 по 2020 годы, чтобы выяснить, как повлияли различные факторы на выручку компаний.

Рассматривая динамику выручки, можно увидеть, что ни в одной из рассмотренных компаний, не наблюдается положительной динамики, так как нефтегазовая отрасль пострадала

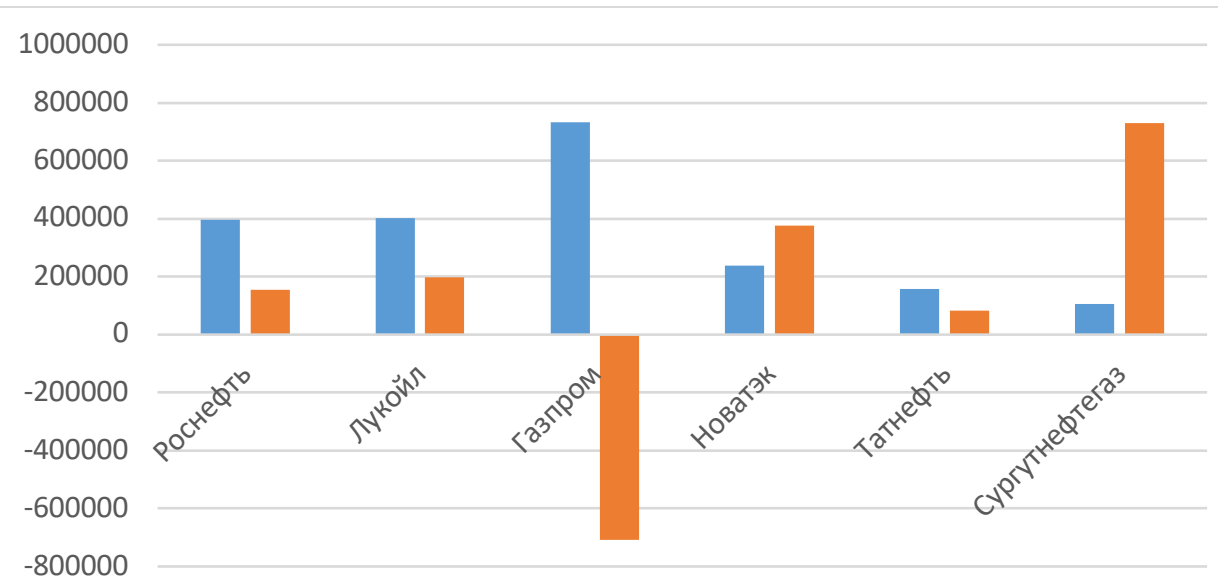

Puc. 1. Динамика чистой прибыли за период 2019-2020 г.г. Источник: составлено авторами 
в России наиболее сильно из-за остановки производств и сокращения потребления ресурсов (см. рис. 2).

Далее проведем оценку финансовой устойчивости по методике Донцовой Л. В. и Никифоровой Н.А., используя следующие финансовые коэффициенты: капитализации, обеспеченности оборотных активов собственными средствами, финансовой независимости (автономии), финансирования, финансовой устойчивости. При расчете коэффициентов использовалась программа Microsoft Excel (см. табл. 1 и 2).

Таким образом, проведя анализ крупнейших нефтегазовых компаний России, были получены следующие результаты:

При оценке значения коэффициента капитализации в компаниях Роснефть, Газпром, Новатэк наблюдалась положительная его динамика, при этом данная тенденция не связана с ростом заемного капитала, такое влияние на финансовый показатель оказала влияние выручка, которая в отчетном году во всех рассмотренных компаниях снизилась, в остальных же компаниях, где чистая прибыль имела положительную динамику за счет не основных видов деятельности, коэффициент капитализации снизился.

Значения коэффициента обеспеченности собственными оборотными средствами в таких организациях как Роснефть, Лукойл, Газпром были отрицательными как в 2019, так и в 2020 годах, и при этом дефицит собственных оборотных средств стал еще значительнее. Если рассматривать динамику коэффициента по крупным компаниям в отрасли, то на протяжении ряда лет средние значения были отрицательными.

Значение коэффициента финансовой независимости во всех компаниях, кроме Роснефти, соответствует типичному значению для данной

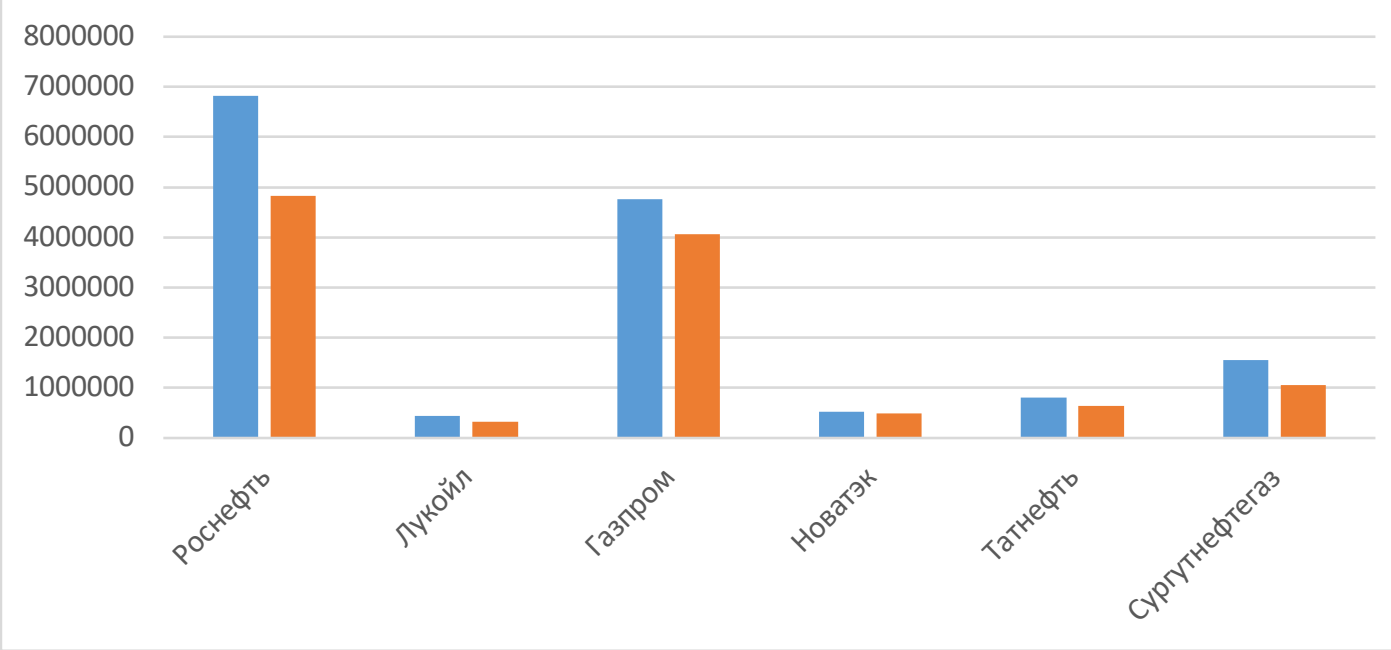

Puc. 2. Динамика выручки за период 2019-2020 г.г. Источник: составлено авторами

Таблица 1. Оценка финансовой устойчивости нефтегазовых компаний с помощью финансовых коэффициентов по данным финансовой отчетности за 2020 год

\begin{tabular}{|l|l|l|l|l|l|l|}
\hline Показатели & Роснефть & Лукойл & Газпром & Новатэк & Татнефть & $\begin{array}{l}\text { Сургутне- } \\
\text { фтегаз }\end{array}$ \\
\hline Коэффициент капитализации & 1,7975 & 0,4505 & 0,5372 & 0,2785 & 0,3221 & 0,0531 \\
\hline $\begin{array}{l}\text { Коэффициент обеспеченности } \\
\text { собственными оборотными } \\
\text { средствами }\end{array}$ & $-2,3754$ & $-0,4578$ & $-0,4705$ & 0,4654 & 0,5396 & 0,8453 \\
\hline $\begin{array}{l}\text { Коэффициент финансовой } \\
\text { независимости (автономии) }\end{array}$ & 0,3575 & 0,6894 & 0,6505 & 0,7822 & 0,7564 & 0,9496 \\
\hline $\begin{array}{l}\text { Коэффициент финансирова- } \\
\text { ния }\end{array}$ & 0,5563 & 2,2199 & 1,8615 & 3,5904 & 3,1048 & 18,8400 \\
\hline $\begin{array}{l}\text { Коэффициент финансовой } \\
\text { устойчивости }\end{array}$ & 0,7986 & 0,8522 & 0,8563 & 0,8823 & 0,8415 & 0,9730 \\
\hline
\end{tabular}

Источник: составлено авторами 
Таблица 2. Оценка финансовой устойчивости нефтегазовых компаний с помощью финансовых коэффициентов по данным финансовой отчетности за 2019 год

\begin{tabular}{|l|l|l|l|l|l|l|}
\hline Показатели & Роснефть & Лукойл & Газпром & Новатэк & Татнефть & $\begin{array}{l}\text { Сургутне- } \\
\text { фтегаз }\end{array}$ \\
\hline $\begin{array}{l}\text { Коэффициент капитали- } \\
\text { зации }\end{array}$ & 1,5143 & 0,4977 & 0,4470 & 0,2522 & 0,4270 & 0,0628 \\
\hline $\begin{array}{l}\text { Коэффициент обеспе- } \\
\text { ченности собственными } \\
\text { оборотными средствами }\end{array}$ & $-2,2542$ & $-0,2751$ & $-0,4380$ & 0,4424 & 0,4193 & 0,7976 \\
\hline $\begin{array}{l}\text { Коэффициент финансовой } \\
\text { независимости }\end{array}$ & 0,3977 & 0,6668 & 0,6911 & 0,7986 & 0,7008 & 0,9409 \\
\hline $\begin{array}{l}\text { Коэффициент финансиро- } \\
\text { вания }\end{array}$ & 0,6604 & 2,0092 & 2,2372 & 3,9649 & 2,3418 & 15,9115 \\
\hline $\begin{array}{l}\text { Коэффициент финансовой } \\
\text { устойчивости }\end{array}$ & 0,7872 & 0,7956 & 0,8696 & 0,9149 & 0,7846 & 0,9664 \\
\hline
\end{tabular}

Источник: составлено авторами

отрасли - доля собственных средств в рассматриваемых компаниях в среднем составляет около $75 \%$. В Роснефти доля собственных средств в 2020 году составила 36\%, что еще раз подчеркивает то обстоятельство, что заемный капитал превалирует над собственным.

Коэффициент финансирования показывает, за счет каких средств финансируется деятельность организаций, а поскольку во всех рассматриваемых организациях, кроме Роснефти, превалируют собственные источники, то и значение коэффициента капитализации соответствует критерию (больше 0,7$)$ и является типичным для нефтегазовой отрасли.

Значение коэффициента финансовой устойчивости во всех рассматриваемых компаниях соответствует нормативу для нефтегазовой отрасли, что свидетельствует о том, что добыча нефти и газа финансируется за счет устойчивых источников.

Далее рассмотрим результаты финансового состояния по сводным критериям оценки бухгалтерского баланса, каждой рассматриваемой организации был присвоен класс финансового состояния. При присвоении рейтинга учитывались следующие финансовые коэффициенты:

- коэффициент абсолютной ликвидности;

- коэффициент критической оценки;

- коэффициент текущей ликвидности;

- доля оборотных средств в активах;

- коэффициент обеспеченности собственными оборотными средствами;

- коэффициент капитализации;

- коэффициент финансовой независимости;

- коэффициент финансовой устойчивости.

Исходя из данных табл. 3 можно сделать вывод о том, что пять из шести исследуемых организаций имеют II класс финансового состояния, причем такое состояние можно характеризовать как нормальное, при котором значения некоторых финансовых коэффициентов отстают от нормативов, но организации в целом достаточно финансово устойчивы. Организация Роснефть по проведенной рейтинговой оценке относится к IV классу финансового состояния, которое можно характеризовать как неустойчивое, структура капитала в Роснефти неудовлетворительная, платежеспособность находится на нижней границе допустимых значений, риск неплатежей достаточно велик.

Таблица 3. Рейтинговая оценка финансового состояния организаций нефтегазовой отрасли

\begin{tabular}{|l|l|l|l|l|l|}
\hline \multirow{2}{*}{ № п/п } & Организация & \multicolumn{2}{l|}{ Сумма баллов по рейтингу } & \multicolumn{2}{l|}{ Класс финансовой устойчивости } \\
\cline { 3 - 6 } & & 2019 & 2020 & 2019 & 2020 \\
\hline 1 & Роснефть & 23,4 & 28,6 & IV & IV \\
\hline 2 & Лукойл & 78,9 & 76,3 & II & II \\
\hline 3 & Газпром & 74,1 & 74,5 & II & II \\
\hline 4 & Новатэк & 95,4 & 96,3 & II & II \\
\hline 5 & Татнефть & 82,6 & 89 & II & II \\
\hline 6 & Сургутнефтегаз & 95,8 & 95,6 & II & II \\
\hline
\end{tabular}

Источник: составлено авторами 


\section{Заключение}

Несмотря на существующий среднесрочный потенциал роста добычи нефти в России, ее добыча была сокращена из-за обязательств, принятых на себя РФ по сокращению добычи нефти по сделке с ОПЕК +, что непосредственно оказало свое влияние на финансовые результаты, а как следствие, и на рентабельность нефтяной отрасли в целом.

Рассмотрев динамику выручки организаций нефтегазового сектора однозначно можно говорить о влиянии пандемии на нефтегазовую отрасль. Ознакомившись с отчетностью организаций можно сделать вывод о сокращении инвестиций в нефтесервисные компании, которые пострадали в первую очередь, так как спрос на углеводороды в 2020 году значительно снизился, что позволило крупнейшим нефтегазовым компаниям на российском рынке не инвестировать в геологоразведку.

Все рассмотренные компании, за исключением Газпрома, получили чистую прибыль, причем положительной динамике чистой прибыли способствовал рост доходов от прочей деятельности, что позволило организациям сохранить свою финансовую устойчивость в период действия ограничений по сделке ОПЕК+ и сокращении спроса при пандемии.

Кроме того, после восстановления спроса на энергоресурсы нефтесервисные компании получат отложенный спрос на свои услуги, так как организации в поисках новых месторождений направят свои ресурсы в геологоразведку. При этом введенные санкции по закупке импортного оборудования и технологий, могут существенно повлиять не только на инвестиции в геологоразведку, но и на качество добываемой нефти, так как для поиска новых месторождений необходима закупка импортного оборудования, а принятые меры по импортозамещению пока не принесли ожидаемых результатов.
Длительный цикл производства оборудования для разработки новых месторождений (особенно технологии по добычи нефти на арктическом шельфе и на глубоководных водах) заставляют инвестировать в развитие отечественных технологий уже сегодня, так как многие проекты сегодня заморожены под действием санкций. Пока рост добычи нефти происходит за счет открытия месторождений, разработка которых проводилась еще до ввода санкций в 2014 году.

Газовый кризис в Европе и не заполненные в полной мере хранилища газа позволили получить ПАО «Газпром» сверх доходы: чистая прибыль по итогам 9 месяцев 2021 года стала рекордной за всю историю деятельности организации и составила 1580 млн. руб., чистая выручка за вычетом акцизов и таможенных пошлин от экспорта газа в Европу составила 2461 млн. руб., что на 216,8\% больше чем за аналогичный период предыдущего года, при этом средняя цена за тысячу кубических метров газа по данным отчетности выросла на 194\% и составила 17838 млн. руб., а как следствие налоговые доходы бюджета от добычи и экспорта газа возрастут в 2021 году. Данная ситуация может служить примером положительного влияния санкций на крупнейшего поставщика газа в Европу.

Так, в связи с апрельским увеличением добычи нефти по сделке с ОПЕК+ в 2021 году и окончанием строительства Северного потока 2 в октябре 2021 года можно говорить о том, что нефтегазовые доходы российского бюджета будут восстанавливаться на докризисный уровень, а рост фьючерсов на газ в связи с кризисом на европейском рынке и невозможностью увеличения транспортировки газа через Украину в связи с 80\% изношенностью украинского оборудования увеличит не только финансовые результаты компаний, но и налоговые поступления в бюджет страны.

\section{Библиографический список}

1. Шнайдер, О.В., Иззука, Т.Б. Финансовые и нефинансовые показатели отчетности экономических субъектов: важность, задачи и решение. Russian Journal of Management. 2019;7(2)46-50.

2. Донцова Л.В.Никифорова Н.А. Анализ бухгалтерской (финансовой) отчетности 6-е изд. М.: Издательство «Дело и сервис» 2019

3. Иванова, Л.И. Анализ финансовой отчетности: учебное пособие / Иванова Л. И., Бобылева А. С. - Москва: КноРус, 2022. - 331 с. - ISBN 978-5-406-08674-2. - URL: https://book.ru/book/940648 (дата обращения: 03.12.2021). - Текст: электронный

4. Евгения Воропаева Бум газовых цен в Европе обернулся «Газпрому» рекордной прибылью/ РБК / [Электронный ресурс]// URL: https://www.rbc.ru/business/29/11/2021/61a48ef29a79476f21279f9f 
5. Геннадий Камышников, Виталий Михальчук, Камила Жилилова Обзор нефтесервисного рынка в России / [Электронный ресурс] // URL: https://www2.deloitte.com/content/dam/Deloitte/ru/Documents/energyresources/Russian/oil-gas-survey-russia-2020.pdf

6. Нефтегазовый сектор имеет перспективы к восстановлению / Финам / [Электронный ресурc]// URL: https://www.finam.ru/international/imdaily/neftegazovyiy-sektor-imeet- perspektivy-k-vosstanovl eniyu-20210217-130314/

7. Перспективы российской нефтедобычи:жизнь под санкциями / Энергетический центр бизнес-школы «Сколково» [Электронный ресурс]// URL: https://energy.skolkovo.ru/downloads/documents/SEneC/research04-ru.pdf

8. Горькие плоды ОПЕК+ О последствиях подписанного Россией соглашения о сокращении добычи нефти/ LENTA.RU/ [Электронный ресурс]// URL: https://lenta.ru/articles/2020/09/04/neft/

9. Сергей Пирогов Перспективы рынка нефти в 2022 году/ Investing.com/ [Электронный ресурс]// URL: https://ru.investing.com/analysis/article-200286052

10. https://minenergo.gov.ru/ - официальный сайт Министерства энергетики Российской Федерации

11. https://www.moex.com/ официальный сайт Московской биржи

12. https://www.rosneft.ru/ официальный сайт компании ПАО Роснефть

13. https://lukoil.ru/ официальный сайт компании ПАО Лукойл

14. https://www.gazprom.ru/ официальный сайт ПАО Газпром

15. https://www.novatek.ru/ официальный сайт ПАО Новатэк

16. https://www.tatneft.ru/ официальный сайт ПАО Татнефть

17. https://www.surgutneftegas.ru/ официальный сайт ПАО Сургутнефтегаз

18. https://spark-interfax.ru/ официальный сайт международная информационная группа «СПАРК» 